\title{
UNSTEADY LAMINAR MIXED CONVECTION BOUNDARY \\ LAYER FLOW NEAR A VERTICAL WEDGE DUE TO OSCILLATIONS IN THE FREE-STREAM AND SURFACE TEMPERATURE
}

\author{
N.C. ROY and Md. A. HOSSAIN* \\ Department of Mathematics, University of Dhaka \\ Dhaka-1000, BANGLADESH \\ E-mail: anwar.cfd@gmail.com
}

\author{
S. HUSSAIN \\ Department of Mathematics and Natural Sciences, BRAC University \\ BANGLADESH
}

\begin{abstract}
The unsteady laminar boundary layer characteristics of mixed convection flow past a vertical wedge have been investigated numerically. The free-stream velocity and surface temperature are assumed to be oscillating in the magnitude but not in the direction of the oncoming flow velocity. The governing equations have been solved by two distinct methods, namely, the straightforward finite difference method for the entire frequency range, and the extended series solution for low frequency range and the asymptotic series expansion method for high frequency range. The results demonstrate the effects of the Richardson number, Ri, introduced to quantify the influence of mixed convection and the Prandtl number, Pr, on the amplitudes and phase angles of the skin friction and heat transfer. In addition, the effects of these parameters are examined in terms of the transient skin friction and heat transfer.
\end{abstract}

Key words: mixed convection, boundary layer flow, vertical wedge, free-stream oscillation.

\section{Introduction}

Over a few decades, oscillating flow and heat transfer under the influence of free-stream oscillation have been the focus of research due to its occurrence in many interesting and important fluid-mechanical problems, for example, the accelerating and decelerating phases of missile flight, the intermittent flow in an engine during unstable combustion, heat transfer encountered in liquid rocket and turbo-jet engines, and thermal failure of the resonance tube heating in which the effect of heat generation appears to be significant. Many studies [1-8] were devoted to unsteady laminar boundary layer characteristics (e.g., fluctuating skinfriction and heat transfer) between 1950 and 1980 as a result of its practical applications. Due to lack of the development of numerical simulation up to the early 1970's, this issue was mainly investigated theoretically. As a result, a simplified problem was formulated of the actual technological problems and the complexity in obtaining the solutions was thus circumvented by imposing restrictions on oscillation amplitude or a frequency [1]. Accordingly, a body of knowledge about the problems was not fully uncovered. Even, there is still scope for further investigation about this large subject.

Lighthill [2] first initiated the investigation of how a boundary layer responds to fluctuations of the external velocity about a steady mean. It was noted that the analysis is applicable to the fluctuations in relative velocity that arise from oscillations of a body parallel to a steady oncoming stream and when a body

\footnotetext{
* Correspondence should be addressed to E-mail: anwar.cfd@gmail.com
} 
having variable speed as well as constant orientation and direction moves through a fluid at rest. Using this concept, Glauert [3] examined the laminar boundary layer on oscillating plates and cylinders. A comprehensive description shows how the results for a flat plate can be used to illustrate the boundary layer in the neighbourhood of the front stagnation point on a cylinder making transverse or rotational oscillations.

Ishigaki published a series of papers [1, 4-7] on unsteady laminar boundary layer flow in the presence of free-stream oscillations. He investigated the time-mean characteristics of the periodic boundary layer near a two-dimensional stagnation point [4]. Later, Ishigaki [5] focused on the temperature field in the laminar boundary layer near a two-dimensional stagnation point due to main-stream oscillation. He observed a time-mean modification in the temperature field through two effects, such as, the heat convection by the secondary flow induced by the oscillation which consists in the nonlinearity of the governing equation, and the other effect results from the combined influence between the fluctuations of velocity and temperature. Ishigaki [6] theoretically examined the effect of oscillation on the time-mean skin friction and surface temperature of an insulated flat plate taking into account the fluctuating stream velocity and the viscous dissipation in kinetic energy. In the subsequent study of the author [7], the oscillating heat transfer mechanism was investigated assuming the previous problem while the plate is kept at constant temperature instead of being insulated.

From a practical point of view, the flow oscillation is seen not only along the horizontal and vertical plate but also in an inclined plate or wedge-type flow. In this investigation, attention will only be given to flow past a vertical wedge. Gersten [8] theoretically investigated the time-mean heat transfer in a wedge-type flow with small amplitude oscillation and found that that the time-mean heat-transfer rate is smaller than that without oscillation. Kumari and Gorla [9] carried out a boundary layer analysis considering the combined convection along a vertical non-isothermal wedge embedded in a fluid-saturated porous medium. Hossain $e t$ al. [10] examined a steady two dimensional laminar forced flow of a viscous incompressible fluid past a horizontal wedge with uniform surface heat flux. A steady mixed convection boundary layer flow over a vertical wedge with the effect of magnetic field embedded in a porous medium was studied by Kumari et al. [11]. Kandasamy et al. [12] presented the effects of variable viscosity and thermophoresis on magnetohydrodynamics mixed convective heat and mass transfer past a porous wedge in the presence of chemical reaction. However, it should be mentioned here that Nanda and Sharma [13] first analyzed the free convection laminar boundary layers on a flat plate assuming the oscillating plate temperature and isothermal free-stream. Also, the free convection flow and heat transfer from a semi-infinite vertical plate moving arbitrarily in its own plane and having variable surface temperature was examined by Sinha and Singh [14].

Since, in practice, unsteady heat transfer and flow field are encountered in some machinery, so it is expected that both the stream velocity and surface temperature can be oscillatory. Moreover, the effect of buoyancy driven flow has to be incorporated into the mathematical formulation as the aforementioned engineering problems take place under the gravitational field. Nevertheless, the previous studies did not consider mixed convection induced by buoyancy force and the oscillating free-stream velocity and surface temperature. Thus the purpose of this study is to investigate the oscillating laminar boundary layer of mixed convection flow past a vertical wedge under the influence of free-stream and surface temperature oscillations. The effects of the Richardson number, Ri, introduced to measure the effect of mixed convection and the Prandtl number, Pr, have been presented in terms of amplitudes and phase angles of skin-friction and heat transfer. The transient skin-friction and heat transfer are also shown for different values of Ri and Pr.

\section{Mathematical formulation}

Let us consider a two-dimensional unsteady laminar boundary layer flow of an incompressible fluid with constant properties. To describe the flow configuration, we assume that $x$ denotes the distance along the surface from the leading edge, $y$ denotes the distance normal from the surface, $u$ and $v$ are the corresponding velocity components, $T$ is the temperature, $t$ is the time, $U$ is the velocity at the edge of the boundary layer, $v$ is the kinematic viscosity, $\alpha$ is the thermal diffusivity, $g$ is the acceleration due to gravity, $\beta$ is the coefficient of volumetric expansion. The coordinate system and the flow configuration are shown in Fig.1. 


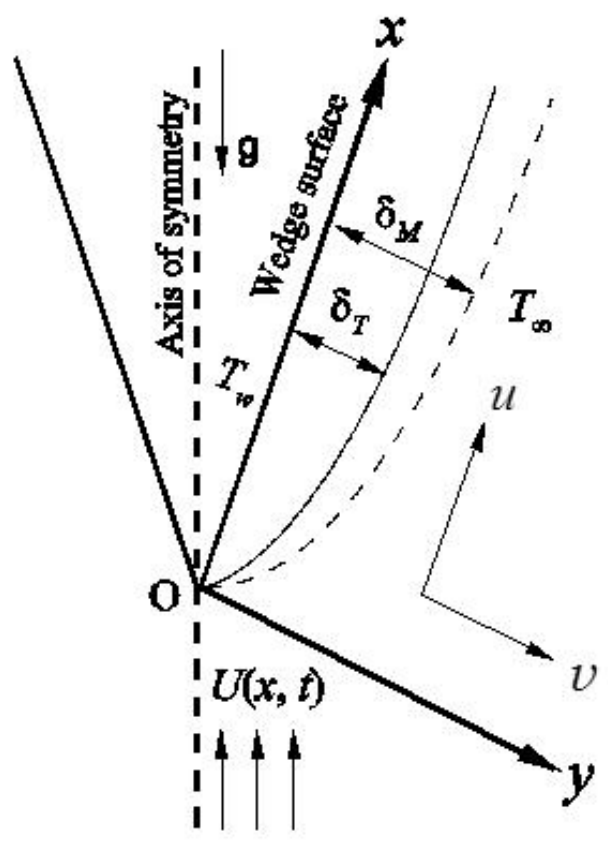

Fig.1. Flow configuration and coordinate system.

Thus the boundary-layer equations for a two-dimensional unsteady laminar boundary layer flow of an incompressible fluid are

$$
\begin{aligned}
& \frac{\partial u}{\partial x}+\frac{\partial v}{\partial y}=0 \\
& \frac{\partial u}{\partial t}+u \frac{\partial u}{\partial x}+v \frac{\partial u}{\partial y}=\frac{\partial U}{\partial t}+U \frac{\partial U}{\partial x}+v \frac{\partial^{2} u}{\partial y^{2}}+g \beta\left(T-T_{\infty}\right) \cos \left(\frac{\pi}{4}\right) \\
& \frac{\partial T}{\partial t}+u \frac{\partial T}{\partial x}+v \frac{\partial T}{\partial y}=\alpha \frac{\partial^{2} T}{\partial y^{2}}
\end{aligned}
$$

The corresponding boundary conditions are

$$
\begin{aligned}
& u=v=0, \quad T=T_{\infty}+\left(T_{w}-T_{\infty}\right)\left(1+\varepsilon e^{i \omega t}\right) \quad \text { at } \quad y=0, \\
& u=U(x, t), \quad T=T_{\infty} \quad \text { as } y \rightarrow \infty .
\end{aligned}
$$

Here, the free-stream velocity $U(x, t)$ is assumed to be of the form

$$
U(x, t)=U_{0} x^{1 / 2}\left(1+\varepsilon e^{i \omega t}\right), \quad \text { as } \quad y \rightarrow \infty .
$$


where, $U_{0}, \varepsilon$ are constant and $\omega$ is the frequency. Based on the continuity Eq.(2.1), we can define the stream function $\psi$ by

$$
u=\frac{\partial \psi}{\partial y}, \quad v=-\frac{\partial \psi}{\partial x}
$$

When $\varepsilon<<1$, the functions $\psi$ and $T$ may be developed in the following forms

$$
\begin{aligned}
& \psi(x, y, t)=\psi_{0}(x, y)+\varepsilon \psi_{l}(x, y) e^{i \omega t}, \\
& T(x, y, t)=T_{0}(x, y)+\varepsilon T_{1}(x, y) e^{i \omega t}
\end{aligned}
$$

where only the real part is to be taken as it has physical meaning. Now we substitute (2.6)-(2.9) into (2.2) and (2.3), and equate the coefficients of $\varepsilon^{0}$ that give

$$
\begin{aligned}
& \frac{\partial \psi_{0}}{\partial y} \frac{\partial^{2} \psi_{0}}{\partial x \partial y}-\frac{\partial \psi_{0}}{\partial x} \frac{\partial^{2} \psi_{0}}{\partial y^{2}}=\frac{1}{2} U_{0}^{2}+v \frac{\partial^{3} \psi_{0}}{\partial y^{3}}+g \beta\left(T_{0}-T_{\infty}\right) \cos \left(\frac{\pi}{4}\right) \\
& \frac{\partial \psi_{0}}{\partial y} \frac{\partial T_{0}}{\partial x}-\frac{\partial \psi_{0}}{\partial x} \frac{\partial T_{0}}{\partial y}=\alpha \frac{\partial^{2} T_{0}}{\partial y^{2}} .
\end{aligned}
$$

The set of equations for $\psi_{0}$ and $T_{0}$ represents the steady-state solutions that can be determined by the following functions

$$
\psi_{0}=\left(v U_{0}\right)^{1 / 2} x^{3 / 4} f(\eta), \quad \frac{T_{0}-T_{\infty}}{T_{w}-T_{\infty}}=\theta(\eta) ; \quad \eta=\left(\frac{U_{0}}{v}\right)^{1 / 2} x^{-1 / 4} y
$$

Using Eqs (2.12) in Eqs (2.10) and (2.11), we obtain the dimensionless equations

$$
\begin{aligned}
& f^{\prime \prime \prime}+\frac{3}{4} f f^{\prime \prime}-\frac{1}{2}\left(f^{\prime 2}-1\right)+\operatorname{Ri} \theta=0, \\
& \frac{1}{\operatorname{Pr}} \theta^{\prime \prime}+\frac{3}{4} f \theta^{\prime}=0,
\end{aligned}
$$

with boundary conditions

$$
\begin{aligned}
& f=f^{\prime}=0, \quad \theta=1 \quad \text { at } \quad \eta=0, \\
& f^{\prime}=1, \quad \theta=0 \quad \text { as } \quad \eta \rightarrow \infty .
\end{aligned}
$$

Substituting the expressions (2.6)-(2.9) into Eqs (2.2), (2.3) and equating the coefficients of $\varepsilon$ give equations for time-dependent components $\psi_{l}$ and $T_{l}$ as 


$$
\begin{aligned}
& i \omega \frac{\partial \psi_{1}}{\partial y}+\frac{\partial \psi_{0}}{\partial y} \frac{\partial^{2} \psi_{1}}{\partial x \partial y}+\frac{\partial \psi_{1}}{\partial y} \frac{\partial^{2} \psi_{0}}{\partial x \partial y}-\frac{\partial \psi_{0}}{\partial x} \frac{\partial^{2} \psi_{1}}{\partial y^{2}}-\frac{\partial \psi_{1}}{\partial x} \frac{\partial^{2} \psi_{0}}{\partial y^{2}}= \\
& =i \omega U_{0} x^{1 / 2}+U_{0}^{2}+v \frac{\partial^{3} \psi_{1}}{\partial y^{3}}+g \beta T_{1}, \\
& i \omega T_{1}+\frac{\partial \psi_{0}}{\partial y} \frac{\partial T_{1}}{\partial x}+\frac{\partial \psi_{1}}{\partial y} \frac{\partial T_{0}}{\partial x}-\frac{\partial \psi_{0}}{\partial x} \frac{\partial T_{1}}{\partial y}-\frac{\partial \psi_{1}}{\partial x} \frac{\partial T_{0}}{\partial y}=\alpha \frac{\partial^{2} T_{1}}{\partial y^{2}}
\end{aligned}
$$

The associated boundary conditions become

$$
\begin{aligned}
& \psi_{1}=\frac{\partial \psi_{1}}{\partial y}=0, \quad T_{1}=T_{w}-T_{\infty} \quad \text { at } \quad y=0 \\
& \frac{\partial \psi_{1}}{\partial y}=U_{0} x^{1 / 2}, \quad T_{1}=0 \quad \text { as } \quad y \rightarrow \infty .
\end{aligned}
$$

To non-dimensionalize Eqs (2.17) and (2.18), we introduce the following expressions

$$
\psi_{1}=\left(v U_{0}\right)^{1 / 2} x^{3 / 4} F(\xi, \eta), \quad \frac{T_{1}}{\left(T_{w}-T_{\infty}\right)}=\Theta(\xi, \eta), \quad \text { as } \quad y \rightarrow \infty .
$$

Using Eqs (2.12) and (2.21) into Eqs (2.17) and (2.18), we obtain

$$
\begin{aligned}
& F^{\prime \prime \prime}+\frac{3}{4}\left(f F^{\prime \prime}+f^{\prime \prime} F\right)-f^{\prime} F^{\prime}+i \xi\left(1-F^{\prime}\right)+\operatorname{Ri} \Theta+1=\frac{1}{2} \xi\left(f^{\prime} \frac{\partial F^{\prime}}{\partial \xi}-f^{\prime \prime} \frac{\partial F}{\partial \xi}\right), \\
& \frac{1}{\operatorname{Pr}} \Theta^{\prime \prime}+\frac{3}{4}\left(f \Theta^{\prime}+\theta^{\prime} F\right)-i \xi \Theta=\frac{1}{2} \xi\left(f^{\prime} \frac{\partial \Theta}{\partial \xi}-\theta^{\prime} \frac{\partial F}{\partial \xi}\right) .
\end{aligned}
$$

Here $\xi=\omega x^{1 / 2} / U_{0}, \operatorname{Gr}_{x}=g \beta\left(T_{w}-T_{\infty}\right) \cos (\pi / 4) x^{3} / v^{2}$ is the Grashof number, $\operatorname{Re}_{x}=U_{0} x^{3 / 2} / v$ is the Reynolds number and $\operatorname{Pr}=v / \alpha$ is the Prandtl number.

The boundary conditions for Eqs (2.22) and (2.23) are

$$
\begin{aligned}
& F=F^{\prime}=0, \quad \Theta=1 \quad \text { at } \quad \eta=0, \\
& F^{\prime}=1, \quad \Theta=0 \quad \text { as } \quad \eta \rightarrow \infty .
\end{aligned}
$$

Now we obtain the appropriate equations for all Pr by introducing

$$
(f, F)=(1+\operatorname{Pr})^{-3 / 4}(\hat{f}, \hat{F}) \quad \text { and } \quad \hat{\eta}=(1+\operatorname{Pr})^{1 / 4} \eta
$$

into the set of Eqs (2.13)-(2.14) and (2.22)-(2.23) as well as the corresponding boundary conditions. Thus we get 


$$
\begin{aligned}
& (1+\operatorname{Pr}) \hat{f}^{\prime \prime \prime}+\frac{3}{4} \hat{f f}^{\prime \prime}-\frac{1}{2}\left\{\hat{f}^{\prime 2}-(1+\operatorname{Pr})\right\}+\operatorname{Ri}(1+\operatorname{Pr}) \hat{\theta}=0, \\
& \frac{1+\operatorname{Pr}}{\operatorname{Pr}} \hat{\theta}^{\prime \prime}+\frac{3}{4} \hat{f} \hat{\theta}^{\prime}=0
\end{aligned}
$$

with the boundary conditions

$$
\begin{aligned}
& \hat{f}=\hat{f}^{\prime}=0, \quad \hat{\theta}=1 \quad \text { at } \quad \hat{\eta}=0, \\
& \hat{f}^{\prime}=(1+\operatorname{Pr})^{1 / 2}, \hat{\theta}=0 \quad \text { as } \quad \hat{\eta} \rightarrow \infty
\end{aligned}
$$

and

$$
\begin{aligned}
& (1+\operatorname{Pr}) \hat{F}^{\prime \prime \prime}+\frac{3}{4}\left(\hat{f} \hat{F}^{\prime \prime}+\hat{f}^{\prime \prime} \hat{F}\right)-\hat{f} \hat{F}^{\prime}+i \xi\left\{(1+\operatorname{Pr})-\sqrt{1+\operatorname{Pr}} \hat{F}^{\prime}\right\}+ \\
& +\operatorname{Ri}(1+\operatorname{Pr}) \hat{\Theta}+(1+\operatorname{Pr})=\frac{1}{2} \xi\left(\hat{f}^{\prime} \frac{\partial \hat{F}^{\prime}}{\partial \xi}-\hat{f}^{\prime \prime} \frac{\partial \hat{F}}{\partial \xi}\right), \\
& \frac{1+\operatorname{Pr}}{\operatorname{Pr}} \hat{\Theta}^{\prime \prime}+\frac{3}{4}\left(\hat{f} \hat{\Theta}^{\prime}+\hat{\theta}^{\prime} \hat{F}\right)-i \xi \sqrt{1+\operatorname{Pr}} \hat{\Theta}=\frac{1}{2} \xi\left(\hat{f}^{\prime} \frac{\partial \hat{\Theta}}{\partial \xi}-\hat{\theta}^{\prime} \frac{\partial \hat{F}}{\partial \xi}\right),
\end{aligned}
$$

with the boundary conditions

$$
\begin{aligned}
& \hat{F}=\hat{F}^{\prime}=0, \quad \hat{\Theta}=1 \quad \text { at } \hat{\eta}=0, \\
& \hat{F}^{\prime}=(1+\operatorname{Pr})^{1 / 2}, \quad \hat{\Theta}=0 \quad \text { as } \hat{\eta} \rightarrow \infty .
\end{aligned}
$$

Once the solutions of the sets of Eq.(2.27) to Eqs (2.30) and (2.31) to Eq.(2.34) are known, the values of the physical quantities, namely, the skin friction and the rate of heat transfer at the surface of the plate, are readily obtained. These are important not only from the physical point of view but also from the experimental point of view. In this study, the results will be presented in terms of amplitudes and phases of the skin friction and the heat transfer rate having the following relations

$$
A_{u}=\sqrt{\tau_{r}^{2}+\tau_{i}^{2}}, \quad A_{t}=\sqrt{q_{r}^{2}+q_{i}^{2}},
$$

and

$$
\phi_{u}=\tan ^{-1}\left(\frac{\tau_{i}}{\tau_{r}}\right), \quad \phi_{t}=\tan ^{-1}\left(\frac{q_{i}}{q_{r}}\right)
$$

where $\left(\tau_{r}, \tau_{i}\right)$ and $\left(q_{r}, q_{i}\right)$ are the corresponding real and imaginary parts of the transverse velocity and temperature gradients at the surface. 


\section{Methods of solution}

The set of Eq.(2.27) to Eq.(2.30) represents the steady mean flow and temperature fields which are solved by employing the straightforward finite difference method for different values of the physical parameters Pr and Ri. The resulting solutions are then used in finding the solutions of Eq.(2.31) to Eq.(2.34) that provide the oscillating parts of the flow and the temperature fields. With a view to validating the numerical solutions Eq.(2.31) to Eq.(2.34) are also solved using the extended series expansion method for small $\xi$ and the asymptotic method for large $\xi$. Details of the solutions are discussed in the following sections.

\subsection{Extended series solutions (ESS) for small $\xi$}

In order to obtain the effect of mixed convection flow near the leading edge, the result based on the finite number of terms in the series is only valid in a very small range of frequencies. Thus

$$
\begin{aligned}
& \hat{F}(\xi, \hat{\eta})=\sum_{m=0}^{\infty}(2 i \xi)^{m} F_{m}(\hat{\eta}), \\
& \hat{\Theta}(\xi, \hat{\eta})=\sum_{m=0}^{\infty}(2 i \xi)^{m} \Theta_{m}(\hat{\eta}) .
\end{aligned}
$$

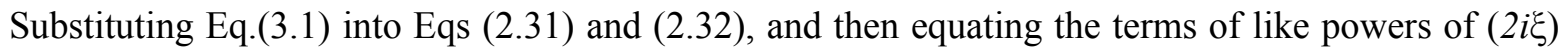
to zero, the following pairs of ordinary differential equations are obtained

$$
\begin{aligned}
& (1+\operatorname{Pr}) F_{0}^{\prime \prime \prime}+\frac{3}{4}\left(\hat{f} F_{0}^{\prime \prime}+\hat{f}^{\prime \prime} F_{0}\right)-\hat{f}^{\prime} F_{0}^{\prime}+\operatorname{Ri}(1+\operatorname{Pr}) \Theta_{0}+1+\operatorname{Pr}=0, \\
& \frac{1+\operatorname{Pr}}{\operatorname{Pr}} \Theta_{0}^{\prime \prime}+\frac{3}{4}\left(\hat{f} \Theta_{0}^{\prime}+\hat{\theta}^{\prime} F_{0}\right)=0 \\
& (1+\operatorname{Pr}) F_{l}^{\prime \prime \prime}+\frac{3}{4} \hat{f} F_{l}^{\prime \prime}+\frac{5}{4} \hat{f}^{\prime \prime} F_{1}-\frac{3}{2} \hat{f}^{\prime} F_{1}^{\prime}+\operatorname{Ri}(1+\operatorname{Pr}) \Theta_{1}+\frac{1}{2}(1+\operatorname{Pr})=\frac{1}{2} \sqrt{1+\operatorname{Pr}} F_{0}^{\prime}, \\
& \frac{1+\operatorname{Pr}}{\operatorname{Pr}} \Theta_{1}^{\prime \prime}+\frac{3}{4} \hat{f} \Theta_{1}^{\prime}+\frac{5}{4} \hat{\theta}^{\prime} F_{1}-\frac{1}{2} \hat{f}^{\prime} \Theta_{1}=\frac{1}{2} \sqrt{1+\operatorname{Pr}} \Theta_{0} \quad \text { for } \quad m \geq 2, \\
& (1+\operatorname{Pr}) F_{m}^{\prime \prime \prime}+\frac{3}{4} \hat{f} F_{m}^{\prime \prime}+\left(\frac{3}{4}+\frac{m}{2}\right) \hat{f}^{\prime \prime} F_{m}-\left(1+\frac{m}{2}\right) \hat{f}^{\prime} F_{m}^{\prime}+\operatorname{Ri}(1+\operatorname{Pr}) \Theta_{m}=\frac{1}{2} \sqrt{1+\operatorname{Pr}} F_{m-1}^{\prime}, \\
& \frac{1+\operatorname{Pr}}{\operatorname{Pr}} \Theta_{m}^{\prime \prime}+\frac{3}{4} \hat{f} \Theta_{m}^{\prime}+\left(\frac{3}{4}+\frac{m}{2}\right) \hat{\theta}^{\prime} F_{m}-\frac{m}{2} \hat{f}^{\prime} \Theta_{m}=\frac{1}{2} \sqrt{1+\operatorname{Pr}} \Theta_{m-1}
\end{aligned}
$$

The corresponding boundary conditions are

$$
F_{m}(0)=F_{m}^{\prime}(0)=\Theta_{m}(0)=0, \quad \Theta_{0}(0)=1,
$$




$$
F_{m}^{\prime}(\infty)=(1+\operatorname{Pr})^{1 / 2}, \quad \Theta_{m}(\infty)=0
$$

Here primes denote derivative with respect to $\hat{\eta}$.

Evidently, Eq.(3.2) to Eq.(3.7) are linear, but coupled, and so these are solved independently pairwise one after another. In this study, the implicit Runge-Kutta-Butcher [15] initial value solver together with Nachtsheim-Swigert [16] iteration scheme is utilized to solve Eq.(3.2) to Eq.(3.7), up to $O\left(\xi^{10}\right)$.

\subsection{Asymptotic solutions (ASS) for large $\xi$}

This section concerns the behavior of the solutions of Eqs (2.31) and (2.32) when $\xi$ is large. As the frequency of surface temperature oscillation becomes very high, the boundary layer response should be confined in a very thin region adjacent to the surface. Thus, as the frequency approaches infinity, the solution becomes independent of $x$. Now, a series solution in the high frequency range, utilizing the limiting solution as the zero-th order approximation, is sought. Accordingly, the following transformations are introduced in Eqs (2.31) and (2.32)

$$
F(\xi, \hat{\eta})=\xi^{-1 / 2} \varphi(\xi, Y), \quad \Theta(\xi, \hat{\eta})=\Theta(\xi, Y), \quad Y=\xi^{1 / 2} \hat{\eta}
$$

Thus we have

$$
\begin{aligned}
& (1+\operatorname{Pr}) \frac{\partial^{3} \varphi}{\partial Y^{3}}+\frac{3}{4} \xi^{-1 / 2} f \frac{\partial^{2} \varphi}{\partial Y^{2}}+\xi^{-1}\left(1-f^{\prime} \frac{\partial \varphi}{\partial Y}\right)+\frac{1}{2} \xi^{-3 / 2} f^{\prime \prime} \varphi+ \\
& +i\left\{(1+\operatorname{Pr})-\sqrt{1+\operatorname{Pr}} \frac{\partial \varphi}{\partial Y}\right\}+\operatorname{Ri}(1+\operatorname{Pr}) \xi^{-1} \Theta= \\
& =\frac{1}{2}\left\{f^{\prime}\left(\frac{\partial^{2} \varphi}{\partial Y \partial \xi}+\frac{Y}{2 \xi} \frac{\partial^{2} \varphi}{\partial Y^{2}}\right)-\xi^{-1 / 2} f^{\prime \prime}\left(\frac{\partial \varphi}{\partial \xi}+\frac{Y}{2 \xi} \frac{\partial \varphi}{\partial Y}\right)\right\} \\
& \frac{1+\operatorname{Pr}}{\operatorname{Pr}} \frac{\partial^{2} \Theta}{\partial Y^{2}}+\frac{3}{4} \xi^{-1 / 2} f^{\prime} \frac{\partial \Theta}{\partial Y}+\frac{1}{2} \xi^{-3 / 2} \theta^{\prime} \varphi-i \sqrt{1+\operatorname{Pr} \Theta}= \\
& =\frac{1}{2}\left\{f^{\prime}\left(\frac{\partial^{2} \varphi}{\partial Y \partial \xi}+\frac{Y}{2 \xi} \frac{\partial^{2} \varphi}{\partial Y^{2}}\right)-\xi^{-1 / 2} \theta^{\prime}\left(\frac{\partial \varphi}{\partial \xi}+\frac{Y}{2 \xi} \frac{\partial \varphi}{\partial Y}\right)\right\}
\end{aligned}
$$

For small values of $\hat{\eta}$, we can expand the solutions of Eqs (2.13) and (2.14) in the power series

$$
\begin{aligned}
& \hat{f}=a_{2} \hat{\eta}^{2}+a_{3} \hat{\eta}^{3}+a_{4} \hat{\eta}^{4}+a_{5} \hat{\eta}^{5}+\cdots, \\
& \theta=b_{0}+b_{1} \hat{\eta}+b_{2} \hat{\eta}^{2}+b_{3} \hat{\eta}^{3}+b_{4} \hat{\eta}^{4}+b_{5} \hat{\eta}^{5}+\cdots
\end{aligned}
$$

Using Eqs (3.13) and (3.14) into Eqs (2.13)-(2.16) gives

$$
a_{2}=\frac{1}{2} f^{\prime \prime}(0), \quad b_{0}=\theta(0), \quad b_{1}=\theta^{\prime}(0) \cdots
$$

Now the solutions of Eqs (3.11) and (3.12) can be obtained in the following forms 


$$
\varphi(\xi, Y)=\sum_{m=0}^{\infty} \xi^{-m / 2} E_{m}(Y), \quad \Theta(\xi, Y)=\sum_{m=0}^{\infty} \xi^{-m / 2} L_{m}(Y) .
$$

Substituting Eqs (3.15) into Eqs (3.11) and (3.12), and equating the like powers of $\xi$, we obtain

$$
\begin{aligned}
& E_{0}^{\prime \prime \prime}-\frac{i}{\sqrt{1+\operatorname{Pr}}} E_{0}^{\prime}=-i, \\
& E_{1}^{\prime \prime \prime}-\frac{i}{\sqrt{1+\operatorname{Pr}}} E_{1}^{\prime}=0, \\
& E_{2}^{\prime \prime \prime}-\frac{i}{\sqrt{1+\operatorname{Pr}}} E_{2}^{\prime}=-\left(1+\operatorname{Ri} L_{0}\right), \\
& E_{3}^{\prime \prime \prime}-\frac{i}{\sqrt{1+\operatorname{Pr}}} E_{3}^{\prime}=-\frac{a_{2}}{4(1+\operatorname{Pr})}\left(Y^{2} E_{0}^{\prime \prime}-6 Y E_{0}^{\prime}+4 E_{0}\right)-\operatorname{Ri} L_{1}
\end{aligned}
$$

and

$$
\begin{aligned}
& L_{0}^{\prime \prime}-\frac{i \operatorname{Pr}}{\sqrt{1+\operatorname{Pr}}} L_{0}=0, \\
& L_{1}^{\prime \prime}-\frac{i \operatorname{Pr}}{\sqrt{1+\operatorname{Pr}}} L_{1}=0, \\
& L_{2}^{\prime \prime}-\frac{i \operatorname{Pr}}{\sqrt{1+\operatorname{Pr}}} L_{2}=0, \\
& L_{3}^{\prime \prime}-\frac{i \operatorname{Pr}}{\sqrt{1+\operatorname{Pr}}} L_{3}=-\frac{\operatorname{Pr}}{4(1+\operatorname{Pr})}\left\{a_{2} Y^{2} L_{0}^{\prime}+b_{1}\left(Y E_{0}^{\prime}+2 E_{0}\right)\right\}
\end{aligned}
$$

The associated boundary conditions are

$$
\begin{aligned}
& E_{m}(0)=E_{m}^{\prime}(0)=0, \quad E_{0}^{\prime}(\infty)=(1+\operatorname{Pr})^{1 / 2}, \\
& E_{m}^{\prime}(\infty)=0, \text { for } m=0,1, \ldots \\
& L_{0}(0)=1, L_{m}(0)=L_{m}(\infty)=0, \text { for } m=1,2, \ldots
\end{aligned}
$$

Solving the above equations, we can find the expressions for $F^{\prime \prime}(\xi, 0)$ and $\Theta^{\prime}(\xi, 0)$ as

$$
(1+\operatorname{Pr})^{1 / 4} \xi^{-1 / 2} F^{\prime \prime}(\xi, 0)=\sum_{m=0}^{\infty} \xi^{-m / 2} E_{m}^{\prime \prime}(0)
$$




$$
(1+\operatorname{Pr})^{-1 / 4} \xi^{-1 / 2} \Theta^{\prime}(\xi, 0)=\sum_{m=0}^{\infty} \xi^{-m / 2} L_{m}{ }^{\prime}(0)
$$

where

$$
\begin{aligned}
& E_{0}{ }^{\prime \prime}(0)=(1+\operatorname{Pr})^{1 / 4} r, \quad E_{1}^{\prime \prime}(0)=0, \\
& E_{2}^{\prime \prime}(0)=\frac{(1+\operatorname{Pr})^{1 / 4}\left(G_{0}-G_{1}\right)}{(1-\operatorname{Pr}) r^{2}}, \quad E_{3}^{\prime \prime}(0)=-\frac{9 a_{2}}{16 r^{2}}, \cdots \\
& L_{0}^{\prime}(0)=-\frac{r \sqrt{\operatorname{Pr}}}{(1+\operatorname{Pr})^{1 / 4}}, \quad L_{1}^{\prime}(0)=0, \quad L_{2}^{\prime}(0)=0, \\
& L_{3}^{\prime}(0)=\frac{G_{2}+G_{3}}{8 r^{2}(1+\sqrt{\operatorname{Pr}})^{2} \sqrt{1+\operatorname{Pr}}}, \cdots
\end{aligned}
$$

with

$$
\begin{aligned}
& r=\sqrt{i}, \quad G_{0}=r\{(1-\operatorname{Pr})+\mathrm{Ri}\}, \quad G_{1}=r \operatorname{Ri} \sqrt{\operatorname{Pr}}, \\
& G_{2}=-\frac{1}{2}(1+\sqrt{\operatorname{Pr}})^{2} a_{2}, \quad G_{3}=2 b_{1} \sqrt{1+\operatorname{Pr}}(4 \sqrt{\operatorname{Pr}}-1) .
\end{aligned}
$$

\section{Results and discussion}

The governing equations of the unsteady laminar mixed convection boundary layer flow past a vertical wedge have been solved by two distinct methods, namely, the straightforward finite difference method for the entire frequency range, and the extended series solution for low frequency range and the asymptotic series expansion method for high frequency range. It is worthwhile to note that the effect of the constant coefficients $(1+\mathrm{Pr})^{1 / 4}$ and $(1+\mathrm{Pr})^{-1 / 4}$ within the definitions of the skin friction and heat transfer (Eqs (3.25) and (3.26)), respectively, have not been included during the presentation of the results .

With a view to validating the numerical solution, a comparison of the amplitudes and phase angles of skin friction obtained by the SFF and the series solutions for small and large $\xi$ is shown in Fig.2. It is evident from the figures that the solutions are in excellent agreement. In addition, Fig.2 exhibits the effects of varying the Prandtl number, $\mathrm{Pr}$, on amplitudes and phase angles of the skin friction. When the Prandtl number is increased, the amplitudes and phase angles of skin friction increase. This is because the Prandtl number becomes high due to either an increase of the kinematic viscosity or a decrease of the thermal diffusivity of the fluid, and the increase of the skin friction is the result of this change of the fluid property. 

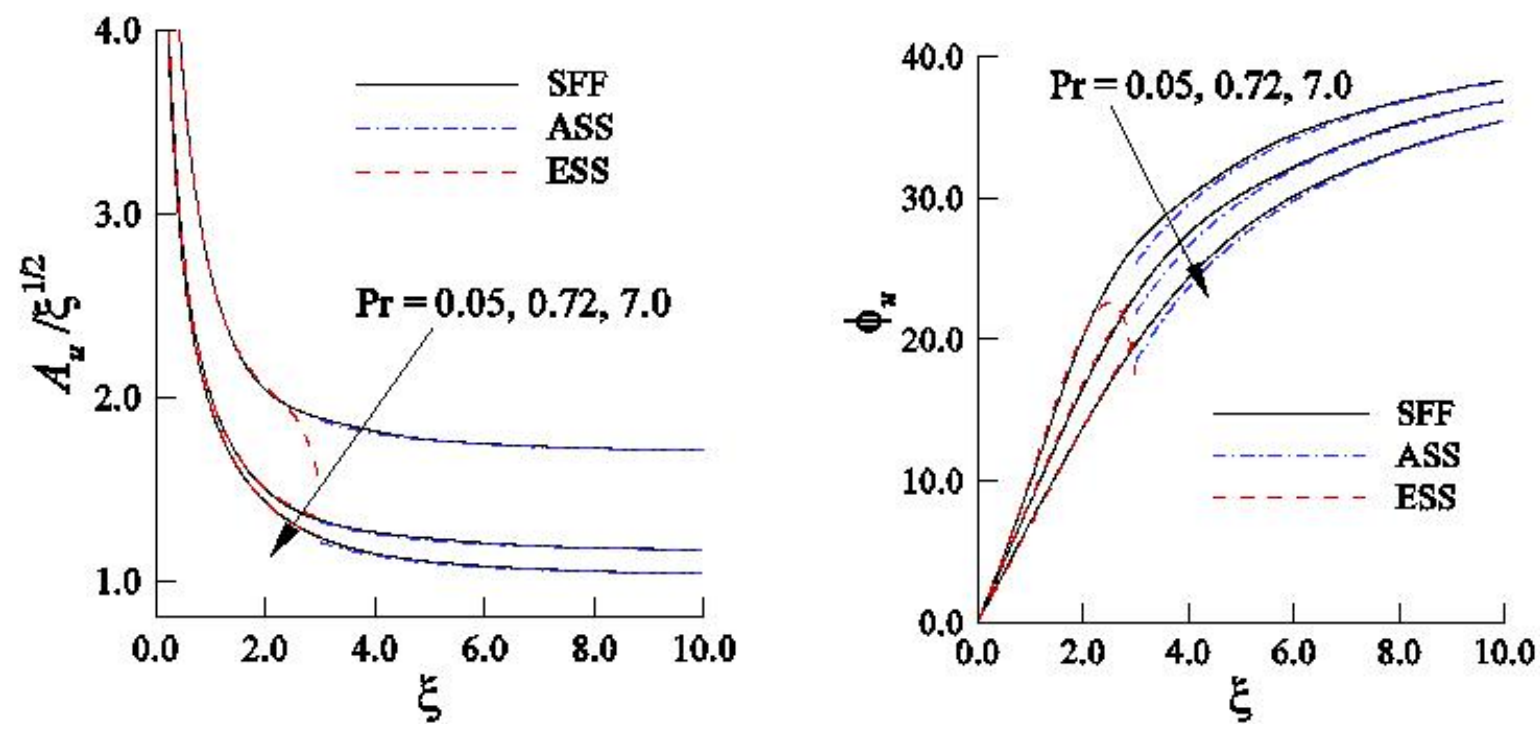

Fig.2. Amplitude and phase angle of skin friction for different values of $\operatorname{Pr}$ while $\mathrm{Ri}=1.0$. The solid (black) lines are for SFF, the dashed (red) lines are for extended series solution (ESS) for small $\xi$, and the dashed-dot (blue) lines are for asymptotic solution (ASS) for large $\xi$.
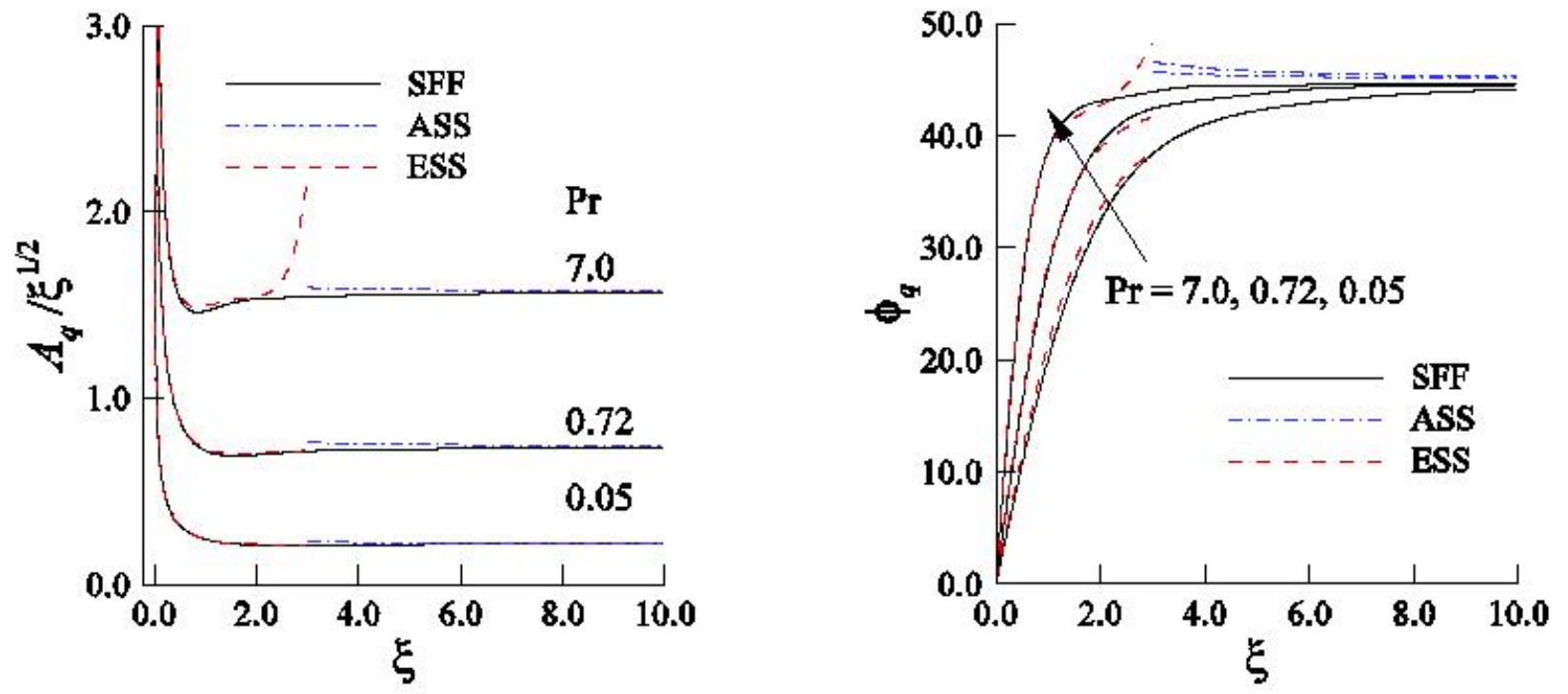

Fig.3. Amplitude and phase angle of heat transfer for different values of Pr while Ri $=1.0$. The solid (black) lines are for SFF, the dashed (red) lines are for extended series solution (ESS) for small $\xi$, and the dashed-dot (blue) lines are for asymptotic solution (ASS) for large $\xi$.

Figure 3 presents a comparison between the SFF and the series solutions for small and large $\xi$ in terms of the amplitudes and phase angles of heat transfer. Evidently, the solutions obtained by the SFF provide a good agreement with the series solutions. Also, the effects of the Prandtl number on the heat transfer are comprehensible from Fig.3. It is seen that the increment of the Prandtl number causes an increase of the amplitudes and phase angles of heat transfer near the leading edge. Since the Prandtl number increases owing to either an increase of the kinematic viscosity or a decrease of the thermal diffusivity of the fluid, hence heat is accumulated near the leading edge that results in the increase of the amplitudes and phase angles of heat transfer. 
Table1. Amplitude and phase angle of skin friction for different Ri while $\operatorname{Pr}=0.72$.

\begin{tabular}{|c|c|c|c|c|}
\hline \multirow[t]{2}{*}{$\xi$} & \multicolumn{2}{|l|}{$A_{u}$} & \multicolumn{2}{|l|}{$\phi_{u}$} \\
\hline & FDS & ESS \& ASS & FDS & ESS \& ASS \\
\hline & \multicolumn{4}{|c|}{$\mathrm{Ri}=0.0$} \\
\hline 0.01 & 15.44288 & $15.45543^{s}$ & 0.12 & $0.16^{s}$ \\
\hline 0.10 & 4.88661 & $4.89135^{s}$ & 1.51 & $1.61^{s}$ \\
\hline 0.50 & 2.22211 & $2.22875^{s}$ & 7.64 & $7.87^{s}$ \\
\hline 1.00 & 1.64739 & $1.65818^{s}$ & 14.45 & $14.66^{s}$ \\
\hline 2.00 & 1.33356 & $1.34454^{s}$ & 24.02 & $23.96^{S}$ \\
\hline 3.00 & 1.24320 & $1.30423^{s}$ & 29.41 & $30.41^{s}$ \\
\hline 4.00 & 1.20444 & $1.19947^{a}$ & 32.69 & $32.45^{a}$ \\
\hline 6.00 & 1.17383 & $1.17256^{a}$ & 36.40 & $36.32^{a}$ \\
\hline 8.00 & 1.16167 & $1.16202^{a}$ & 38.36 & $38.37^{a}$ \\
\hline 10.00 & 1.15546 & $1.15673^{a}$ & 39.58 & $39.64^{a}$ \\
\hline \multicolumn{5}{|c|}{$\mathrm{Ri}=2.0$} \\
\hline 0.01 & 24.19662 & $24.23397^{s}$ & 0.04 & $0.05^{s}$ \\
\hline 0.10 & 7.65152 & $7.66298^{s}$ & 0.46 & $0.46^{s}$ \\
\hline 0.50 & 3.41938 & $3.42219^{s}$ & 2.34 & $2.31^{s}$ \\
\hline 1.00 & 2.41382 & $2.41203^{s}$ & 4.82 & $4.81^{s}$ \\
\hline 2.00 & 1.71211 & $1.70855^{\mathrm{s}}$ & 10.49 & $10.78^{s}$ \\
\hline 3.00 & 1.43917 & $1.44512^{s}$ & 16.71 & $17.28^{s}$ \\
\hline 4.00 & 1.32304 & $1.31958^{a}$ & 22.17 & $21.08^{a}$ \\
\hline 6.00 & 1.24484 & $1.23342^{a}$ & 28.42 & $27.83^{a}$ \\
\hline 8.00 & 1.20174 & $1.19909^{a}$ & 31.77 & $31.67^{a}$ \\
\hline 10.00 & 1.18296 & $1.18188^{a}$ & 34.29 & $34.13^{a}$ \\
\hline \multicolumn{5}{|c|}{$\mathrm{Ri}=4.0$} \\
\hline 0.01 & 32.33106 & $32.39354^{s}$ & 0.01 & $0.01^{s}$ \\
\hline 0.10 & 10.22308 & $10.24231^{s}$ & 0.11 & $0.08^{s}$ \\
\hline 0.50 & 4.55937 & $4.56520^{s}$ & 0.52 & $0.44^{s}$ \\
\hline 1.00 & 3.19704 & $3.19606^{s}$ & 1.17 & $1.05^{s}$ \\
\hline 2.00 & 2.19798 & $2.18774^{s}$ & 3.31 & $3.32^{s}$ \\
\hline 3.00 & 1.74511 & $1.73463^{s}$ & 7.01 & $7.44^{s}$ \\
\hline 4.00 & 1.50073 & $1.48039^{a}$ & 11.97 & $11.57^{a}$ \\
\hline 6.00 & 1.31603 & $1.31690^{a}$ & 21.16 & $20.09^{a}$ \\
\hline 8.00 & 1.26245 & $1.25015^{a}$ & 25.88 & $25.32^{a}$ \\
\hline 10.00 & 1.21931 & $1.21638^{a}$ & 28.83 & $28.79^{a}$ \\
\hline
\end{tabular}

Notes: Here and hereafter, ${ }^{\mathrm{s}}$ and ${ }^{\mathrm{a}}$ represent the solutions due to ESS and ASS respectively. 

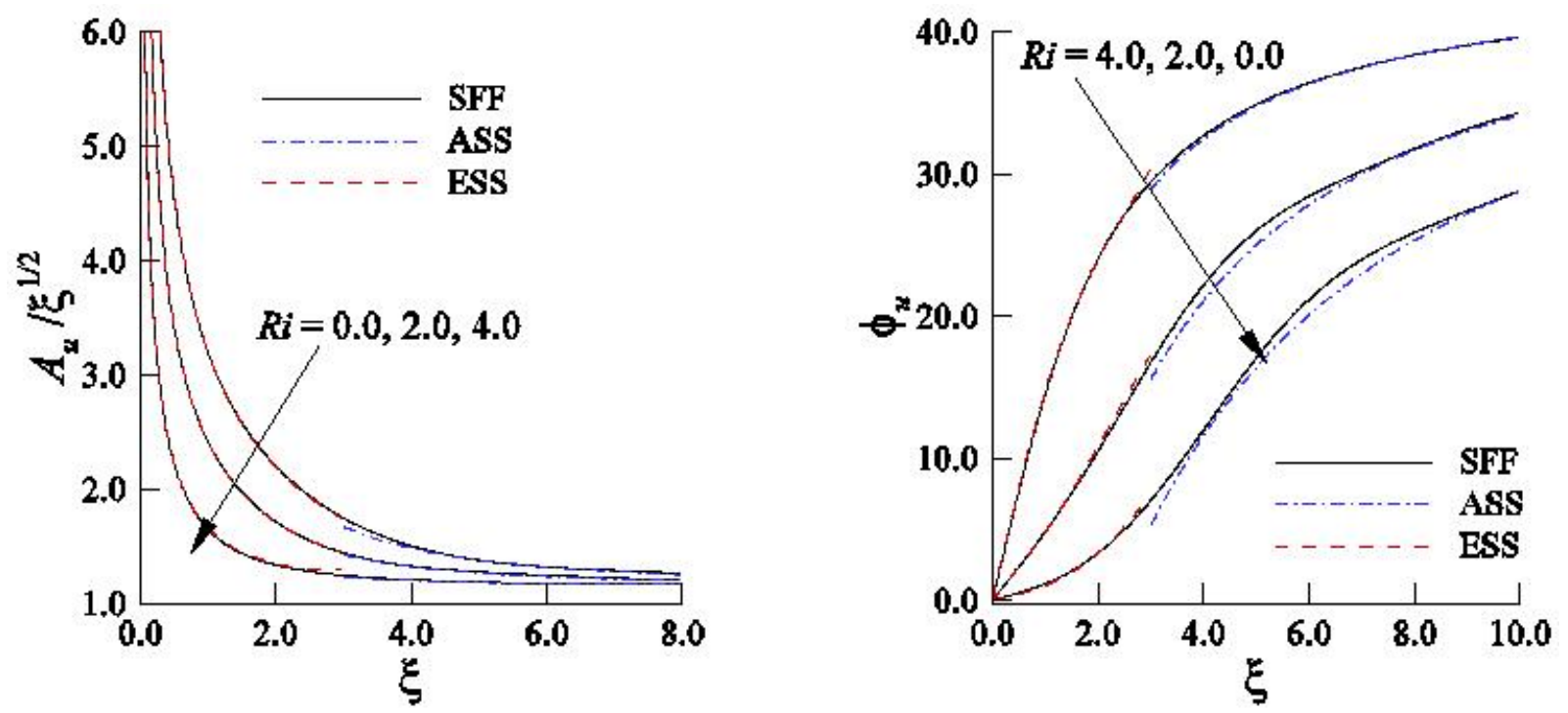

Fig.4. Amplitude and phase angle of skin friction for different values of Ri while $\operatorname{Pr}=0.72$. The solid (black) lines are for SFF, the dashed (red) lines are for extended series solution (ESS) for small $\xi$, and the dashed-dot (blue) lines are for asymptotic solution (ASS) for large $\xi$.

The effects of Richardson's number, Ri, on the amplitudes and phase angles of the skin friction are shown in Fig.4. From the figure and Tab.1, it is observed that for higher Richardson's number, Ri, the amplitudes of skin friction are higher while the phase angles are lower. As Richardson's number, Ri, increases, mixed convection of flow and heat transfer increases. Accordingly, the amplitudes of skin friction are higher for higher Ri. But the rate $\backslash$ of change of skin friction from the leading edge to the downstream region is higher for lower Ri so that the phase angles of skin friction are higher for lower Ri.
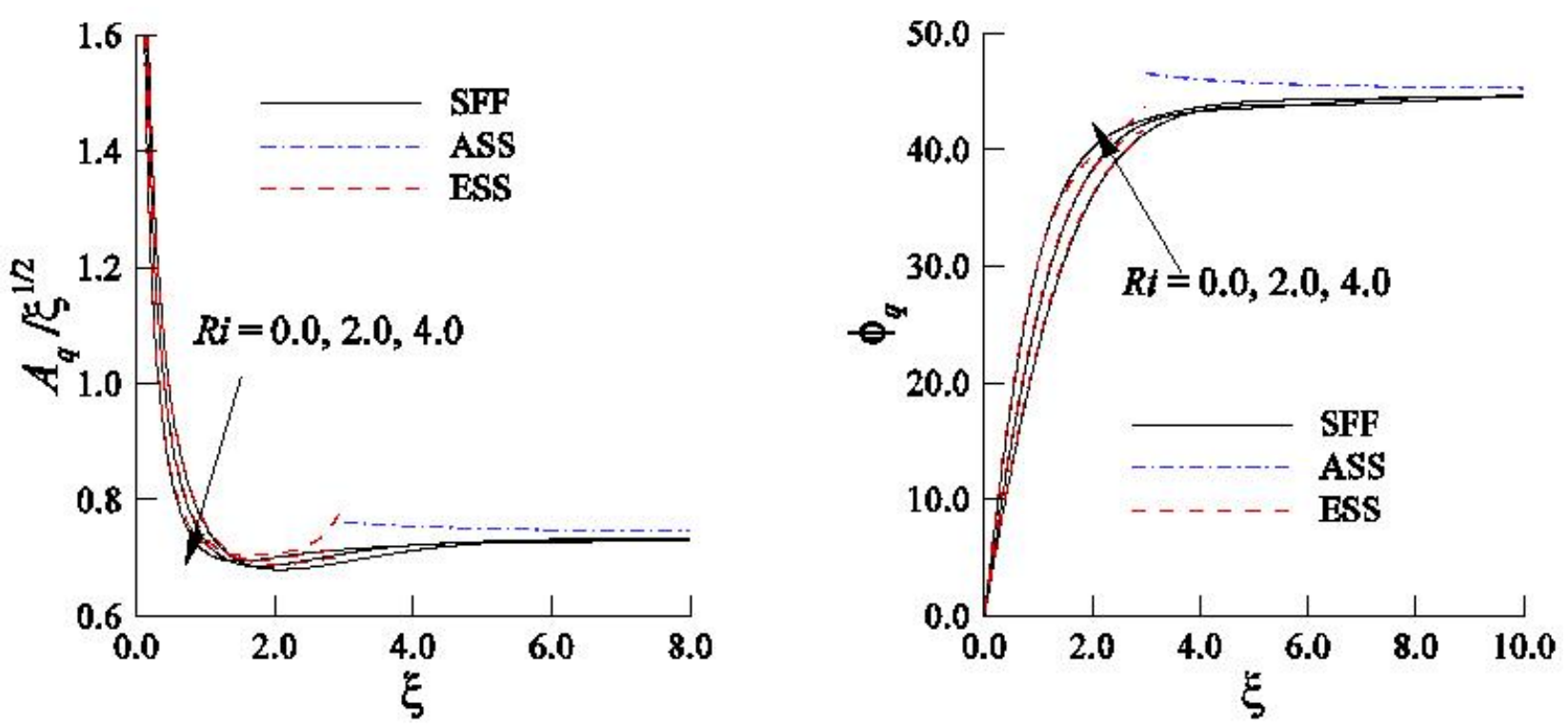

Fig.5. Amplitude and phase angle of heat transfer for different values of Ri while $\operatorname{Pr}=0.72$. The solid (black) lines are for SFF, the dashed (red) lines are for extended series solution (ESS) for small $\xi$, and the dashed-dot (blue) lines are for asymptotic solution (ASS) for large $\xi$. 
Figure 5 exhibits the change of amplitudes and phase angles of heat transfer against Richardson's number, Ri. With an increase of Ri, the amplitudes of heat transfer are higher near the leading edge while the reverse case is observed in the downstream region. On the other hand, for smaller Ri the phase angles are higher near the leading edge and then they become lower in the downstream region. Finally, the amplitudes and phase angles tend to an asymptotic value for all $\mathrm{Ri}$.
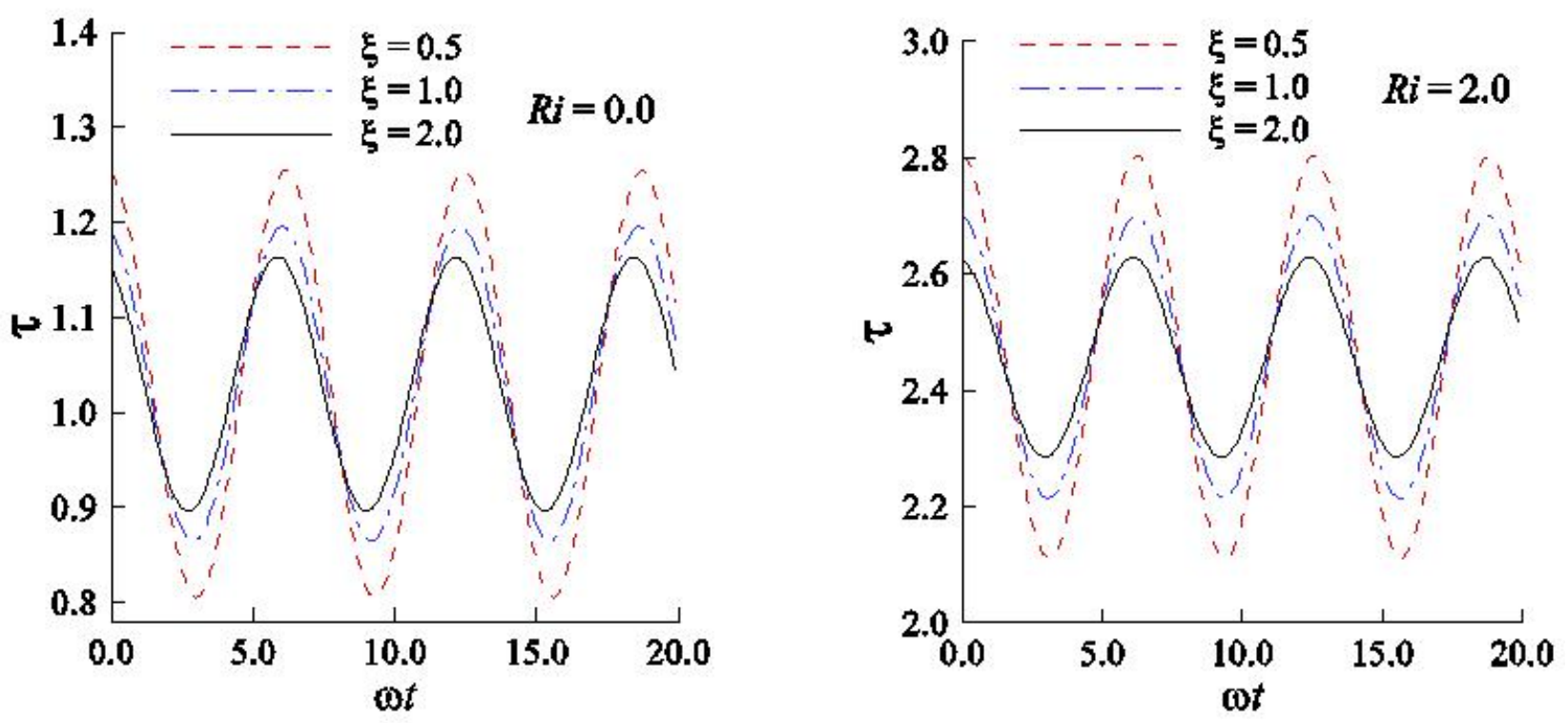

Fig.6. Numerical values of transient skin friction for different values of $\xi$ against $\omega \tau$ while $\operatorname{Pr}=0.72$, $\mathrm{Ri}=0.0$ and 2.0.

\subsection{Effects of different physical parameters on transient skin friction and heat transfer}

From a practical point of view, transient skin friction and heat transfer are important. The reason is that the unsteady behavior of these two properties over a wide region from the leading edge might damage a system. However, the transient skin friction and heat transfer are evaluated here by the following relations

$$
\begin{gathered}
\tau=\tau_{s}+\varepsilon A_{u} \cos \left(\omega t+\phi_{u}\right), \\
q=q_{s}+\varepsilon A_{q} \cos \left(\omega t+\phi_{q}\right)
\end{gathered}
$$

where $\tau_{s}$ and $q_{s}$ are, respectively, the steady-state skin friction and heat transfer.

Numerical values of transient skin friction and heat transfer against $\omega t$ have been presented in Figs 6 and 7, respectively, for $\mathrm{Ri}=0.0$ and 2.0 taking $\mathrm{Pr}=0.72$. It is clear from the figures that the amplitudes of oscillation of transient skin friction, $\tau$, and heat transfer, $q$, increase owing to the increase of Richardson's number, Ri. Also the intensity of oscillation of both transient skin friction and heat transfer subsides quickly away from the leading edge for a small value of Ri compared to a higher value of Ri. The reason is that the impact of mixed convection of flow and heat transfer is strong near the leading edge. 

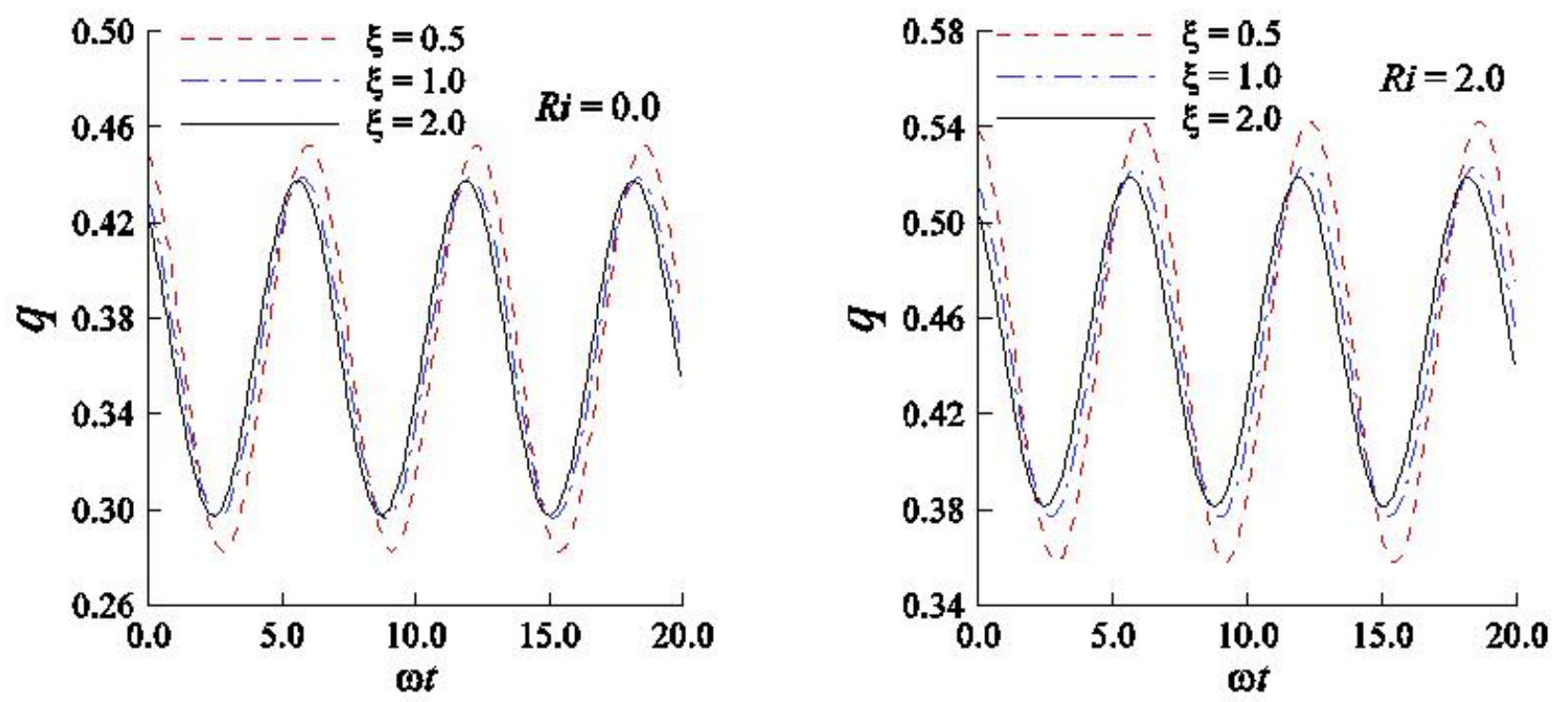

Fig.7. Numerical values of transient heat transfer for different values of $\xi$ against $\omega \tau$ while $\operatorname{Pr}=0.72$, $\mathrm{Ri}=0.0$ and 2.0 .

The effects of varying the Prandtl number, Pr, on the transient skin friction and heat transfer are shown in Figs 8 and 9, respectively. The figures suggest that the amplitudes of oscillation of transient skin friction, $\tau$, and heat transfer, $q$, increase with an increase of the Prandtl number, Pr. The amplitudes of oscillation die down slowly from the leading edge to the downstream region but it happens swiftly for higher Pr.
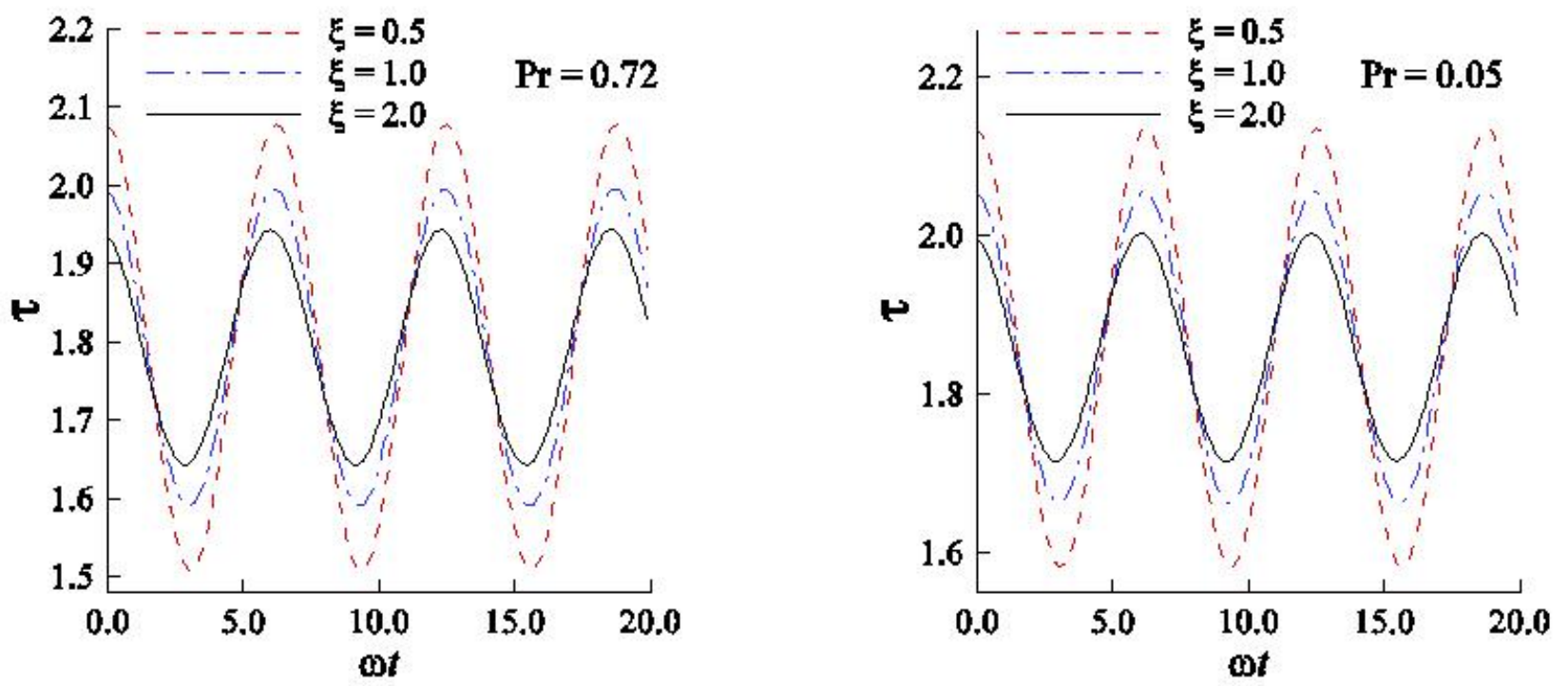

Fig.8. Numerical values of transient skin friction for different values of $\xi$ against $\omega \tau$ while $\mathrm{Ri}=1.0$, $\operatorname{Pr}=0.05$ and 0.72 . 


\section{Conclusions}

The periodic laminar boundary layer mixed convection flow past a vertical wedge with the effect of the fluctuations in the free-stream produced by fluctuations of the oncoming stream has been investigated numerically. The governing equations have been solved by the straightforward finite difference method for the entire frequency range, the extended series solution for low frequency range and the asymptotic series expansion method for high frequency range. The solutions obtained by the straightforward finite difference method provide good agreement with the series solutions. The effects of varying Richardson's number, Ri, introduced to quantify the influence of mixed convection and the Prandtl number, Pr, on the amplitudes and phase angles of the skin friction and heat transfer as well as on the transient skin friction and heat transfer are examined. Based on the results, the following conclusions can be drawn.
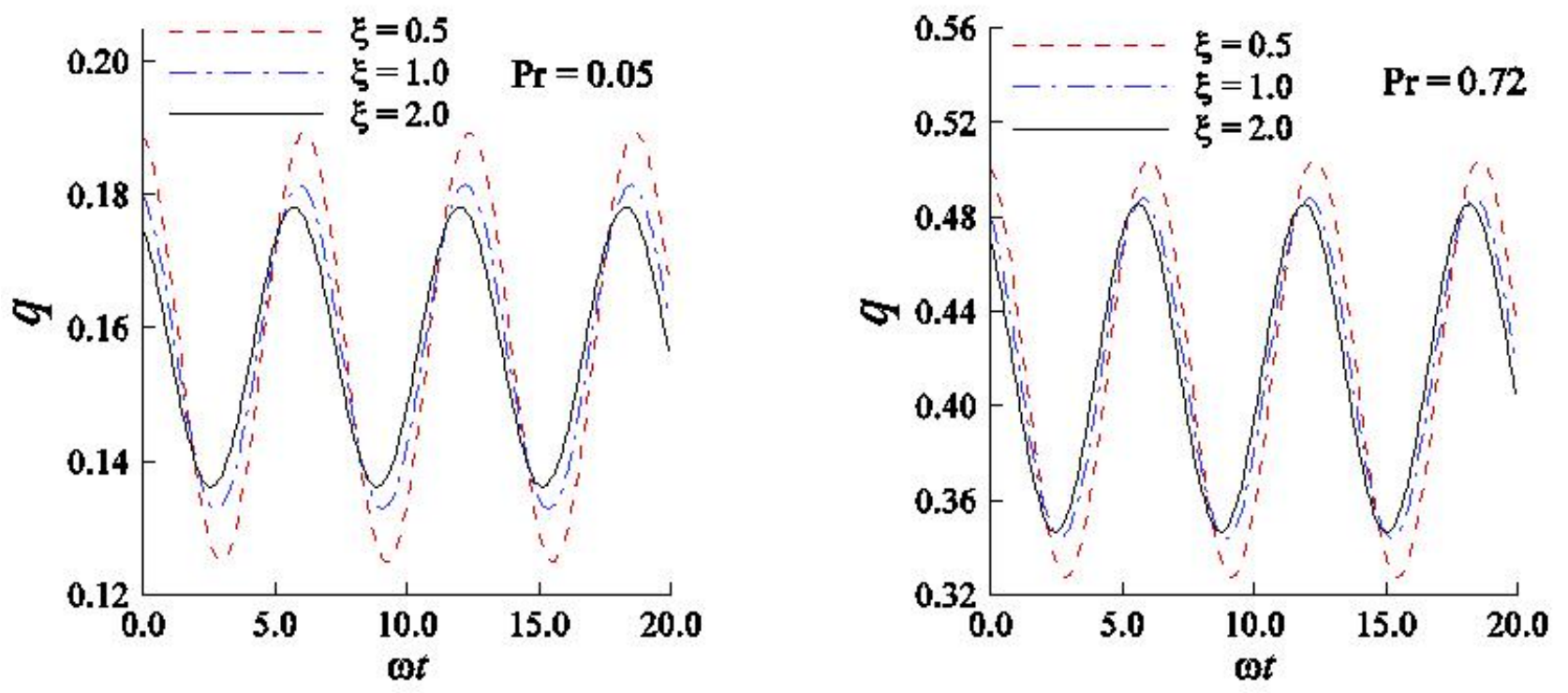

Fig.9. Numerical values of transient heat transfer for different values of $\xi$ against $\omega \tau$ while $\mathrm{Ri}=1.0$, $\operatorname{Pr}=0.05$ and 0.72 .

(1) The amplitudes and phase angles of skin friction and heat transfer increase with an increase of the Prandtl number, Pr;

(2) When Richardson's number, Ri, is increased, the amplitudes of skin friction become large but the phase angles are small. On the other hand, for higher values of Ri, the amplitudes of heat transfer are higher near the leading edge while the reverse circumstance is observed in the downstream region. Moreover, the phase angles are higher near the leading edge for smaller $\mathrm{Ri}$ and then they are lower in the downstream region. Finally, both the amplitudes and phase angles of skin friction and heat transfer reach the corresponding asymptotic values.

(3) The amplitudes of oscillation of transient skin friction, $\tau$, and heat transfer, $q$, are found to increase owing to the increase of Richardson's number, Ri, and Prandtl number, Pr. Moreover, the amplitudes of oscillation of both transient skin friction and heat transfer subside quickly away from the leading edge for a small value of Ri compared to a higher value of Ri while the reverse situation is seen for the Prandtl number, Pr. 


\section{Nomenclature}

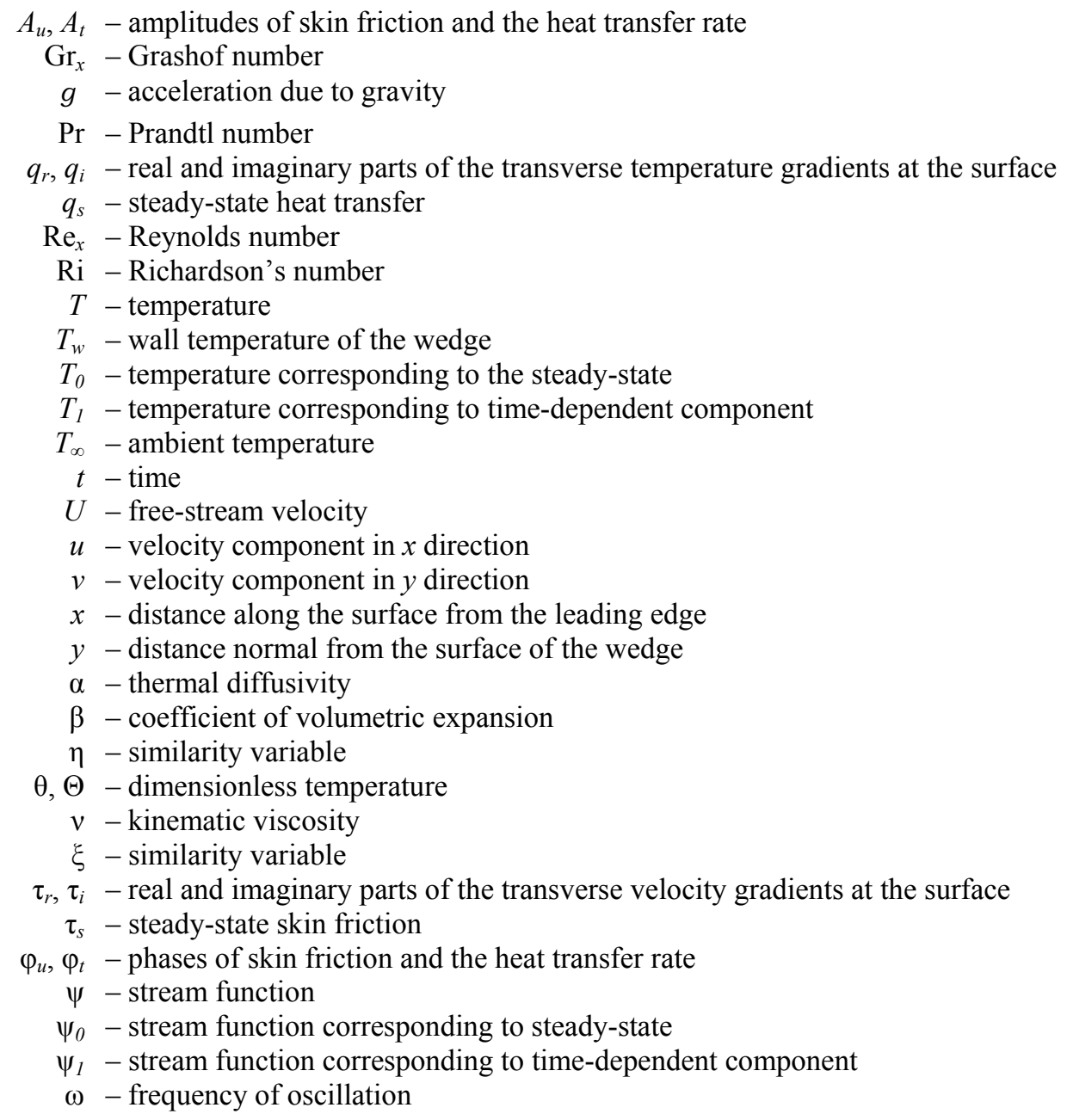

\section{References}

[1] Ishigaki H. (1971): An exact periodic solution of the energy equation. - J. Fluid Mech., vol.50, pp.657-668.

[2] Lighthill M.J. (1954): The response of laminar skin friction and heat transfer to fluctuations in the stream velocity. Proc. R. Soc. Lond. A, vol.224, pp.1-23.

[3] Glauert M.B. (1955): The laminar boundary layer on oscillating plates and cylinders. - J. Fluid Mech., vol.1, pp.97-110.

[4] Ishigaki H. (1970): Periodic boundary layer near a two-dimensional stagnation point. - J. Fluid Mech., vol.43, pp.477-486.

[5] Ishigaki H. (1972): Heat transfer in a periodic boundary layer near a two-dimensional stagnation point. - J. Fluid Mech., vol.56, pp.619-627.

[6] Ishigaki H. (1971): Skin friction and surface temperature of an insulated flat plate fixed in a fluctuating stream. - J. Fluid Mech., vol.46, pp.165-175.

[7] Ishigaki H. (1971): The effect of oscillation on flat plate heat transfer. - J. Fluid Mech., vol.47, pp.537-546.

[8] Gersten K. (1965): Heat transfer in laminar boundary layers with oscillating outer flow. - AGARBograph, vol.97, pp.423-475. 
[9] Kumari M. and Gorla R.S.R. (1997): Combined convection along a non-isothermal wedge in a porous medium.Heat Mass Transf., vol.32, pp.393-398.

[10] Hossain M.A., Munir M.S., Hafiz M.Z. and Takhar H.S. (2000): Flow of a viscous incompressible fluid of temperature dependent viscosity past a permeable wedge with uniform surface heat flux. - Heat Mass Transf., vol.36, pp.333-341.

[11] Kumari M., Takhar H.S. and Nath G. (2001): Mixed convection flow over a vertical wedge embedded in a highly porous medium. - Heat Mass Transf., vol.37, pp.139-146.

[12] Kandasamy R., Muhaimin I. and Khamis A.B. (2009): Thermophoresis and variable viscosity effects on MHD mixed convective heat and mass transfer past a porous wedge in the presence of chemical reaction. - Heat Mass Transf., vol.45, pp.703-712.

[13] Nanda R.S. and Sharma V.P. (1962): Free convection laminar boundary layers in oscillatory flow. - J. Fluid Mech., vol.15, pp.419-428.

[14] Sinha P.C. and Singh P. (1970): Transient free convection flow due to the arbitrary motion of a vertical plate. Proc. Camb. Phil. Soc., vol.67, pp.677-688.

[15] Butcher J.C. (1964): Implicit Runge-Kutta method. - Math. Com., vol.18, pp.50-55.

[16] Naschtsheim P.R. and Sweigert P. (1965): Satisfaction of asymptotic boundary conditions in numerical solution of systems of non-linear equation of boundary layer type. - NASA TN D-3004.

Received: April 26, 2015

Revised: October 29, 2015 